Asian Review of Social Sciences

ISSN: 2249-6319 Vol.7 No.1, 2018, pp. 91-95

(C) The Research Publication, www.trp.org.in

\title{
Flood Mitigation in Developing Countries: A Case Study of India
}

\author{
Md. Karar Ahmad \\ Assistant Professor (Guest), Department of Geography, Jamia Millia Islamia, New Delhi, Delhi, India \\ E-Mail: karar786@gmail.com
}

\begin{abstract}
Floods are the common natural disasters in most of the developing countries, and India isno exception.Due to the geographic and climatic conditions the country remains under threat. Floods have been recurrent phenomenon in many parts of India, causing loss of lives and public property and bringing untold misery to the people. The floods that occurred in India in 2013 were highly catastrophic based on the number of victims. International Federation of Red Cross and Red Crescent Societies, IFRC (2013) continues to steer the evacuation efforts as well as in rescuing the stranded victims. Methods of structural control of floodwater can be grouped into four types; namely, storage, diversion, enhancing channel capacity, and constriction of the water within the channel. The following flood mitigation measures could be adopted to mitigate the adverse impacts of severe floods and to prevent normal floods. Flood walls are constructed out of materials such as concrete or steel in order to control the flow of flood waters and prevent the flooding of specific areas. The construction of floodwalls and embankments has been the traditional means of protecting low lying communities and infrastructure against flooding. Flood hazard maps contain information about the probability or magnitude of an event whereas flood risk maps contain additional information about the consequences. Flood insurance is one of the effective ways in order to cope with the aftermaths of flood events. The Indian government acknowledges the problems the country faces because of the various natural disasters that occur. Consequently, various agencies have been instituted to evaluate the country's exposure to disasters and to develop ways of mitigating or managing the impacts of the disasters.
\end{abstract}

Keywords: Floods, Natural Disasters, Mitigation Measures,Developing Countries, India

\section{INTRODUCTION}

India suffers some of the most tragic natural disasters in the world owing to its geographical location and the number of people is exposed to them. Floods in India occur almost every year with devastating effects on human life and the economy of the country. The topography and climatic conditions of the country make it one of the most vulnerable locations as far as floods are concerned (Kumar and Singh 2012). Floods are one of the most common natural hazards, causing devastating impacts worldwide. Earlier studies have indicated that increased exposure of people and assets, as a result of population increase and economic growth, has caused more damage due to weather-related natural disasters including flooding. Floods have been recurrent phenomenon in many parts of India, causing loss of lives and public property and bringing untold misery to the people, especially those in the rural areas. There is also a larger economic impact, as they derail economic activities, thus affecting growth. Indian continent has weird climatic conditions since it has floods in some parts whereas drought in other parts. Over the years, several expert committees have studied the problems caused by floods and suggested various measures for their management to the government. However, despite the various steps undertaken over the last five decades, the trend of increasing damage and devastation brought by floods has posed serious challenges to the government as well as to the people. The approaches to flood management presently exercised in India also need to give a re-look to have an integrated strategy for policy and management related to floods.

Among all natural disasters, floods are the most frequent to be faced by India. Floods in the eastern part of India due to the notorious rivers like Ganga and its major tributaries such as Yamuna, Ramganaga, Gomti, Ghaghra, Gandak, Kosi, Damodar(U.P., Bihar, Bengal, Orissa) in the recent past, are striking examples. The annual precipitation, in India, including snowfall is estimated at 4,000 Billion Cubic Meter (BCM). Out of this, the seasonal rainfall in monsoon is of the order of 3,000 BCM. The rainfall in India shows great temporal and spatial variations, unequal seasonal distribution and geographical distribution and frequent departures from the normal. As per the information published by different government agencies, flood prone area in India has been increasing dramatically. As reported by Central Water Commission (CWC) under Ministry of Water Resources, government of India, the annual average area affected by floods is 7.563 million ha. This observation was based on data for the period 1953 to 2000, with variability ranging from 1.46 million ha in 1965 to 17.5 million ha in 1978. On an average,floods have affected about 33 million persons between1953-2000.

The flood management mechanisms in India are operational both at central level and state level. The state level mechanism is made up of the water resource department, the Flood Control Board, and State Technical Advisory Committee. The central level mechanismsconsist of bodies such as the Central Water Commission (CWC), the Farakka Barrage Project Authority, the Ganga Flood Control Commission, the National Disaster Management Authority, and the Brahmaputra Board.The work of these agencies plays a significant role in mitigating the flood events time to time. They also look into the implementation of flood control programmes in the flood prone areas in order to save human lives and properties. 


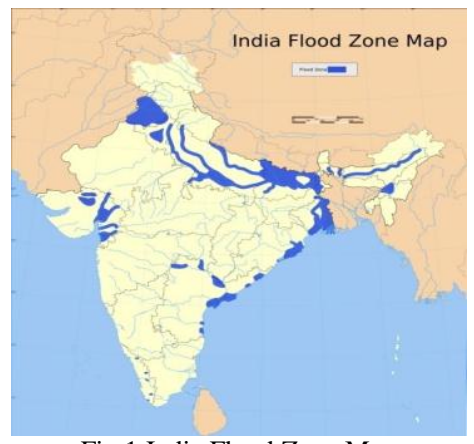

Fig.1 India Flood Zone Map

\section{FLOOD MITIGATION IN DEVELOPING COUNTRIES}

Death tolls from flooding have also risen in many parts of the world. In 2007, floods killed 3,300 people in India and Bangladesh alone. In 2010, flooding killed 2,100 people in Pakistan and another 1,900 in China, while in 2013 some 6,500 people died due to floods in India (ADSR, CRED2015).In the period 1978-2006, Kumar and Singh (2012) indicate that 2,443 floods occurred with a death toll of 44,991. They indicate that the average annual flood fatality is 1551 which translates to 1.5 deaths in a million people. Based on the statistics, it is plausible to argue that India experiences several catastrophic floods in a year. Attri and Tyagi (2010) indicate that the death toll due to floods in India was at 75,000 in a period of 50 years running to 2010. Echoing the gravity of the issue, National Disaster Management Authority of India, NDMAI (2008), indicates that annual average human fatalities due to flooding in India stands at 1,600. The Authority also singles out the flood disaster of 1977 as being the most catastrophic flood event in the history of India, which registered a death toll of 11,316 .

The floods that occurred in India in 2013 may also be ranked as highly catastrophic based on the number of victims. International Federation of Red Cross and Red Crescent Societies, IFRC (2013) continues to steer the evacuation efforts as well as in rescuing the stranded victims. The areas affected are the "Char Dham pilgrimage sites of Badirnath, Kedarnath, Gangotri, and Yamunotri". In reference to a report by Reuters, IFRC (2013) reports that 150 deaths are confirmed in Uttarakhand, a state that was hit hardest by the floods. Approximately 78,000 people remain stranded while hundreds have been left homeless. The IFRC (2013) believes that the death toll is bound to increase due to high number of stranded victims, communication and transportation disruptions as well as the continuing downpour.

The economic damages are also high considering that India is a developing country. Kumar and Singh (2012) place the economic losses at US\$16 billion where the 2000 floods alone attracted economic damages worth US\$1.6 billion. Attri and Tyagi (2010) indicate that the economic losses due to flooding in India, for the last 50 years, were Rs 65000 Crore. The NDMAI (2008) reiterates that the losses incurred due to flooding continue to escalate reaching an annual average of Rs. 4745 Crore in the period 1996-2006, as compared to Rs. 1805 crore in the previous 53 year India's floods occur mainly in the last half of the year with majority of the floods occurring in August (30\%) followed by July (29\%) and September at $20 \%$ of the total floods (Kumar and Singh 2012). The floods are prevalent in the 40 million hectares of the 329 million hectares of Indian lands where the NDMAI (2008) confirms to be flood-prone. The areas that receive high rainfall that result in floods are the regions in central India and the North-western region of the country (IFRC 2013). Uttar Pradesh, Maharashtra, Bihar, and Gujarat are some of the areas that result in the highest number of fatalities between the years 1978-2006 (Kumar and Singh (2012).

\section{MITIGATION STRATEGIES}

It may be pointed out that floods are natural phenomenon and one cannot entirely get rid off them but their impact can be minimised by human's technological skill and engineering developed early warning system and various preventive measures adopted by the governments and other organisations. Methods of structural control of floodwater can be grouped into four types; namely, storage, diversion, enhancing channel capacity, and constriction of the water within the channel. The following flood mitigation measures could be adopted to mitigate the adverse impacts of severe floods and to prevent normal floods.

A. Delay the Runoff: It is true thatman cannot stop high intensity rainfall although it can be delay the return of surface runoff resulting from the high intensity rainfall to the rivers. It may be achieved by large scale reforestation, and afforestation in the hilly source catchment areas of those rivers which are notorious for their disasters floods. Forest delays the return of rainwater to the rivers because these intercept the falling raindrops and also leaf litters and herbaceous ground covers hold waters. These encourage more infiltration of rainwater and therefore trim down marginally the amount of surface overflow. These significantly reduce sediment load of the rivers (Singh\& Singh 2014).

B. Flood walls: Flood walls are constructed out of materials such as concrete or steel in order to control the flow of flood waters and prevent the flooding of specific areas. The construction of floodwalls and embankments has been the traditional means of protecting lowlying communities and infrastructure against flooding.

C. Fills: A fill is an area of land dug out usually behind a levee in order to capture excess flood waters and prevent flood damage to human structures.

D. Dams: The primary purpose of this structure unlike a levee is to retain water, not to manage flood water. A dam can produce hydroelectricity as well as regulate water levels by opening and closing the retaining doors. 


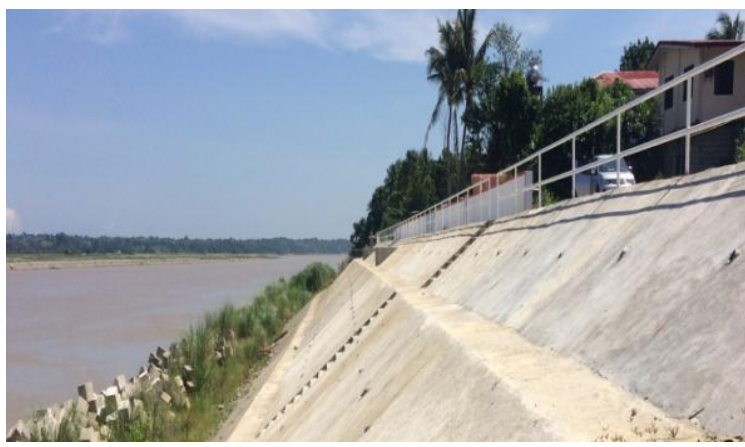

Fig.2 Wall for Flood Mitigation

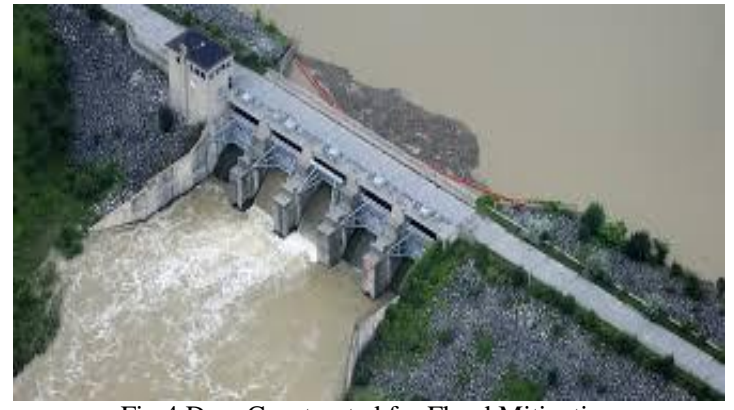

Fig.4 Dam Constructed for Flood Mitigation

E. Levees: A levee is an embankment constructed by engineers out of organic materials such as earth and stone in order to prevent the flooding from a free flowing body of water in a specific location such as a residential community. Levees have been used as a means of structural flood protection for several thousand years. Based on hydraulic principles, it can be shown that for a given flood levees raise the water stage in the leveed channel and upstream of it (Yen 1995).

F. Reservoirs: Reservoirs are the man-made lakes produced as a result of the creation of a dam which can slow the flow of the river downstream. Furthermore, a reservoir can be used for fresh water for a community as well as a preserve for fish and wildlife.

G. Reducing Bed Roughness: This method of mitigation smoothes the bed of the river that allows for the river to flow faster and reduces the likelihood of a flood.

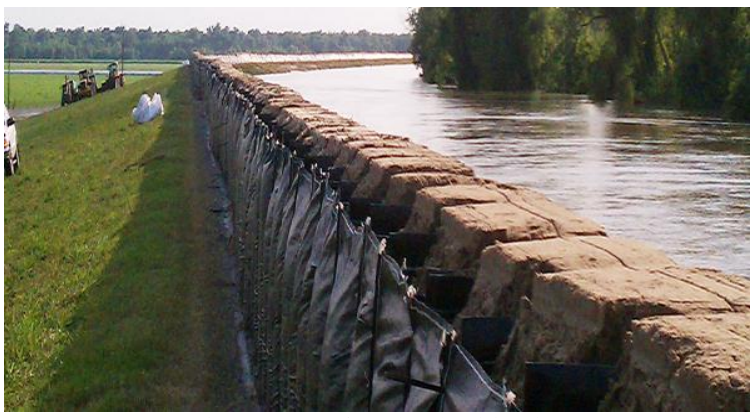

Fig.3 Levees for Flood Mitigation

H. Altering Stream Channels: This strategy is similar to reducing the river bed's roughness. It additionally creates a "V" in the river's bottom. This deepens, as well as increases, the speed of the river, reducing the risk of flooding because the water flows away from the floodplain areas quicker.

I. Land Use Planning and Zoning Tools: Local municipalities can institute zoning laws in their comprehensive plans in order to prevent development of residential and commercial properties in high risk flood prone areas. This planning can further restrict where buildings can be constructed, as well as if these buildings must be flood-proofed. Flood-proofing is a process that involves raising the foundation of the building, berms, flood walls, and/or sealant in order to prevent or reduce the damages inflicted from flood waters. Lastly, local municipalities can impose eminent domain upon a landowner if their property has been deemed as a high recurrence property.

J. Floodplain Mapping: Studies delineating the existing floodplain boundaries, which define the limits of flood hazards. Flood hazard maps contain information about the probability or magnitude of an event whereas flood risk maps contain additional information about the consequences (Moel2009).

K. Education : Homeowners and renters need to educate themselves before moving into a new home to determine if their home is in a floodplain area. This link will give you access to Federal Emergency Management Administration's (FEMA) Map Service Center. By identifying if your potential home is in a floodplain area, you can decrease your risk of being a flood victim.

L. Environmentally Sensitive Area Protection: Areas such as wetlands can be protected by local municipalities by preventing development in those areas. Furthermore, through the use of eminent domain, a local municipality can reclaim areas and return them to their natural states.

M. Flood Forecasting and Warning Methods: By using these methods, such as a stream gauge, local officials can determine whether or not a river or creek will flood based on the level of the water and how quickly it is rising.

N. Mitigation of Flood Risk through Insurance: Flood insurance is one of the most effective ways to cope with the aftermaths of flood events. In absence of an acceptable riskbased assessment framework, flood insurance and its extensive benefits are not fully achieved yet. Consequently, flood insurance is trivially practiced worldwide. To ensure the integration of flood insurance into regular flood management practices, its acceptability by floodplain inhabitants is a prerequisite. Therefore, an admissible insurance rate is a vital factor for the acceptability of insurance policy. Presently, the main objective of flood insurance is to provide support to flood-affected people to reinstate their normal lives after a flood event. Not only the Government of Indiabut also thestates take interest in the implementation of flood insurance to avoid chaos that might raise at large scales because of flood disturbances. Since all extraordinary natural disasters are excluded from traditional 
insurance agreements, flood insurance is generally separated from the regular insurance. Consequently, property owners need to purchase additional policies in order to insure against natural disasters (Andjelkovic, 2001; Collins and Simpson, 2007). Flood insurance differs sharply from the other flood measures. Common flood measures reduce the flood damages, whereas insurance mechanisms mainly diffuse the losses over time (Duivendijk, 1999).

\section{RIVER SYSTEMS AND ASSOCIATED FLOOD PROBLEMS}

The Rivers in India can be broadly divided into the following four regions for a study of flood problem.

\section{Ganga and its tributaries \\ 2. Brahmaputra and its tributaries rivers \\ 3. North West Region rivers \\ 4. Central India and Deccan region}

A. Ganga River Region: The river Ganga and its numerous tributaries such as the Yamuna, the Sone, the Ghaghra, the Gandak, the Kosi and the Mahananda constitute this river region. It covers ten states including Uttaranchal and Uttar Pradesh in its basin area, Jharkand, Bihar, South and Central parts of West Bengal, parts of Haryana, Himachal Pradesh, Rajasthan, Madhya Pradesh and Delhi. The normal annual rainfall in this region varies from $60 \mathrm{~cm}$ to $190 \mathrm{~cm}$ of which more than $80 \%$ occurs during the south west monsoon. The rainfall increases from West to East and from South to North.

The flood problem is largely confined to the areas on the northern bank of the river Ganga. The damage is caused by the northern tributaries of the Ganga by spilling over their banks and changing their courses. Even though the Ganga is a mighty river carrying huge discharges of 57,000 to 85,000 cumec ( 2 to 3 million cusec), the inundation and erosion problems are confined to relatively few places. In general, the flood problem increases from the West to the East and from South to North.In the North Western parts of the region and some eastern parts, there is the problem of drainage congestion. The flooding and erosion problem is serious in the States located in the downstream.In recent years some States which were not traditionally flood prone have also experienced some incidents of heavy floods.

B. Brahmaputra River Region: This region consists of many rivers including Brahamaputra\& Barak and their tributaries covering seven states Assam, Arunachal Pradesh, Meghalaya, Mozoram, Nothern parts of West Bengal, Manipur, Tripura and Nagaland. The catchments of these rivers receive heavy rainfall ranging from $110 \mathrm{~cm}$ to 635 $\mathrm{cm}$. a year that occurs mostly during the months of May / June to September. Consequently, floods in this region are severe and quite frequent. Further, the rocks of the hills, where these rivers originate are fragile and susceptible to erosion thereby causing exceptionally high silt charge in the rivers.
In addition, the region is subject to severe and frequent earthquakes which cause numerous landslides in the hills and upset the regime of the rivers. The predominant problems in this region are the flooding caused by spilling of rivers over their banks, drainage congestion and tendency of some of the rivers to change their courses. In recent years, the erosion along the banks of the Brahmaputra has assumed serious proportions.

C. North West River Region: The Sutlej, the Beas, the Ravi, the Chenab and the Jhelum, the tributaries of Indus are the major rivers flowing from the Himalayas. These rivers carry quite substantial discharge during the monsoon and also large volumes of sediment. They change their courses frequently and leave behind tracts of sandy waste. The region covers the State of Jammu and Kashmir, Punjab and parts of Himachal Pradesh, Haryana and Rajasthan. Compared to the Ganga and the Brahmaputra river region, the flood problem is relatively less in this region. The major problem is the inadequate surface drainage that causes inundation and water logging over vast areas.

D. Central India and Deccan Region: The main rivers in this region are the Narmada, the Tapi, the Mahanadi, the Godavari, the Krishna and the Cauvery. Notably these rivers have well defined stable courses. They have adequate capacity within the natural banks to carry the flood discharge except in the delta area. The lower reaches of the important rivers on the East Coast have been embanked, thus largely eliminating the flood problem.

\section{IMPACTS OF FLOODING}

Flooding in India is known to cause huge losses in terms of lost human lives, destroyed infrastructure, destroyed agricultural products and other commercial entities and health deterioration. IFRC (2013) indicates that the floods result in massive destruction of houses leaving thousands of people homeless. The flood also destroys communication, power, and transportation lines paralyzing human activities and worsening the evacuation process (IFRC 2013).

Other than economic losses, floods in India are also responsible for the spread of waterborne diseases like cholera and diarrhea. According to Joshi et al., (2011), the death toll due to diarrhea in India is a national health concern. They indicate that diarrhea accounts for $17 \%$ of deaths in the indoor pediatric patients, which correspond to 9.3 deaths in every 1000 people in the rural parts of India.

Floods result in spread of diseases, destruction of infrastructure, loss of property, and loss of lives. Perera et al., (2012) give an account of the health impacts of floods citing a number of issues, including disease outbreaks, mental disorders and their associated costs to the country. They affirm that over $50 \%$ of all waterborne diseases in America are caused by floods, which transform most waterways into contagious as they carry disease causing organisms.Perera et al., (2012) also observe that the waterborne diseases pose a big risk to the flood victims 
immediately after the floods have occurred. Water contamination is highly probable when there is floodwater covering large parts of the areas. The resulting conditions include gastrointestinal infections that cause diarrhea and may be fatal (Perera et al.,. 2012). For instance, the 1993 floods inflicted the condition to over 400000 people in Milwaukee and claimed over 100 lives.Other than the immediate health implications of floods, other conditions become apparent long after the floodwater has receded. Perera et al., (2012) cites the mold growth, facilitated by the dampness left behind inside the buildings, which is contagious to asthmatic people. Of the 25 million people living with asthma in America, almost $25 \%$ of the conditions are caused by exposure to mold. The resultant annual cost to the country goes as high as US\$4.5 billion.Mental disorder is another long-term effect of floods where the victims exhibit Post-Traumatic Stress Disorders (PTSD). The condition was witnessed in 1992 in the aftermath of Hurricane Andrew where over 33\% of the adults in the affected regions of Florida suffered depression with over $25 \%$ of the children in the areas affected showing symptoms of PSTD (Perera et al.,. 2012). The incidence of PSTD after major incidence of a natural disaster has been imminent with similar results observed after the Hurricane Katrina hit America in 2005. Mental illnesses are witnessed among the affected populations as shown by the increased incidences of domestic violence, aggressive behavior among minors and higher levels of substance abuse among adults. In the aftermath of Hurricane Katrina, the recorded cases of domestic violence increased among those affected from $4.2 \%$ to $8.3 \%$ (Perera et al.,. 2012, pp. 8).

\section{FLOOD MANAGEMENT POLICIES AND METHODS IN INDIA}

The Indian government acknowledges the problems the country faces because of the various natural disasters that occur. Consequently, various agencies have been instituted to evaluate the country's exposure to disasters and to develop ways of mitigating or managing the impacts of the disasters. The authorities include the High Level Committee on Floods of 1957, the Ministers Committee on Flood Control of 1964, the Rashtriya Barh Ayog of 1980 and the Task Force on Flood Management/Erosion Control of 2004 (NDMAI 2008). The latest is the 2005 formation of the National Disaster Management Authority of India, which is mandated tasked to coordinate all the other bodies involved in disaster mitigation or management in the quest for better results (NDMAI 2008).

The policies that are implemented in India to manage floods are similar to those in many countries. The authorities have acknowledged that floods cannot be prevented from happening regardless of the level of technology employed (Attri and Tyagi 2010). In light of this, the authorities recognize the importance of the protective mechanisms that were in the form of dikes and levees, while also emphasizing on the need to minimize the possible losses in the event that a flood occurs. The NDMAI has initiated a guideline that, among other things, emphasizes on preparedness, prompt response to floods through EWSs, construction of flood resistant structures and flood-proof public structures in the flood prone areas.

\section{CONCLUSION}

Floods inflict many losses to India in terms of lost lives, destroyed properties, as well as health hazards. Efficient management of floods is essential. This includes accurate projection of floods, proper planning of settlements and environmental conservation, which improves on the predictability of torrential rains and storms that cause extensive flooding.It is important to note that flood risk management cannot be treated in isolation, rather it should be a part of community development. In this context, it is essential to build a community's capacity to understand their vulnerabilities, strategies, activities and the role they could play in managing flood risks without relying on external entities. Therefore, the proposed community-based flood hazard-mapping technique could be a good solution for addressing the issues of floods.

\section{REFERENCES}

[1] Attri, and Tyagi, "Climate Profile of India", Contribution to the Indian Network of Climate Change Assessment (NATIONAL COMMUNICATION-II), Ministry of Environment and Forests, India Meteorological Department, New Delhi, 2010.

[2] Andjelkovic, "Guidelines on non-structural measures in urban flood management", Technical documents in hydrology, Paris: UNESCO, International Hydrological Programme, 2001.

[3] Annual Disaster Statistical Review, "The numbers and trends", Centre for Research on the Epidemiology of Disasters (CRED) Institute of Health and Society (IRSS) Universite catholique de Louvain, Belgium, 2015.

[4] Collins \& Simpson, "The impact of climate change on insuring flood risk. Christchurch: Biennial Convention”, Institute of Actuaries of Australia, 2007.

[5] J.V. Duivendijk, "Assessment of flood management options, Assessment of flood control and management options", Cape Town: World Commission on Dams, 1999

[6] Imerzeel, Beek and Bierkens, "Climate change will affect the Asian water towers",Science, Vol.328, pp. 1382-1385, 2010.

[7] Kumar and Singh,"Flood events, Fatalities and Damages in India from 1978 to 2006", Natural Hazards, Vol.2, No. 8, pp.1-20, 2012.

[8] Moel, "Flood maps in Europe - methods, availability and use", Naural Hazards Earth System. Science, Vol.09, pp.289-301, 2009.

[9] NDMAI,"National Disaster Management Guidelines: Management of Floods. New Delhi: National Disaster Management AuthorityMills E. Insurance in a climate of change",Science, Vol. 309, pp. 10401044,2008

[10] YEN, "Hydrometeorology, Impacts, and Management of Extreme Floods", U.S.- Italy Research Workshop on the Perugia (Italy), 1995.

[11] http://www.dpwh.gov.ph/dpwh/news/12097

[12] http://www.barrierforce.com

[13] https://trca.ca/conservation/flood-risk-management

[14] http://www.indiawaterportal.org Accessed on $21^{\text {st }}$ may 2018. 